\title{
Investigation of Rock Failure Pattern in Creep by Digital Speckle Correlation Method
}

\author{
Yunliang Tan, Yanchun Yin, and Tongbin Zhao \\ State Key Laboratory of Mine Disaster Prevention and Control, Shandong University of Science and Technology, \\ Qingdao, Shandong 266590, China
}

Correspondence should be addressed to Yunliang Tan; tylllp@163169.net

Received 9 January 2013; Accepted 11 March 2013

Academic Editor: Z. Barber

Copyright (C) 2013 Yunliang Tan et al. This is an open access article distributed under the Creative Commons Attribution License, which permits unrestricted use, distribution, and reproduction in any medium, provided the original work is properly cited.

In order to study the mechanical characteristics from creep deformation to failure of rock, the tests of uniaxial compression and pushing steel-plate anchored in rock were performed, by using RLJW-2000 servo test synchronizing with Digital Speckle Correlation Method (DSCM). The investigations showed that for a uniaxial compressive specimen, when load arrived at $0.5 \sigma_{c}$, displacement clusters orderly formed, which was ahead of the macrocreep strain occurring in a slight jump mode when load arrived at $0.7 \sigma_{c}$. When the load level arrived at $0.8 \sigma_{c}$, displacement clusters gathered to be a narrow band. After that, the specimen abruptly fractured in a shear mode. In the creep pushing steel-plate test, when pushing force arrived at $25 \mathrm{kN}$, crack began to occur, the horizontal displacement field as well as shear strain field concentrated continuously along the interface between steel-plate and rock, and a new narrow concentrating band gathered in the upper layer. When pushing force arrived at $27.5 \mathrm{kN}$, another new narrow shear deformation band formed in the lower layer. Then, the steel-plate was pushed out quickly accompanying strong creep deformation.

\section{Introduction}

Rock is a typical inhomogeneous and rheologic material. Many investigations showed that the rheological mechanical behaviours of deep rock mass are stronger than those of shallow ones [1-4]. Both rheologic deformation and dilatant rheologic deformation are getting larger and larger as the depth increases $[5,6]$. However, some analytical rheologic models were invalid for many cases, because variety of microstructure exists in rocks. So laboratory experiments are receiving attention. Since the first creep experiment on limestone, shale, and sandstone was finished by Griggs in 1939 [7], many rheologic experiments were finished. The main achievements were as follows: (a) it is found that rock creep rate had three types: steady increase, constant, and steady [8]; (b) some rock creep empirical formulas were obtained in laboratory [9-11]; (c) rock creep damage evolving mechanism was understood [12-14].

The rock complexity attributes to random heterogeneous components, defects or fissures, and so forth. This causes creep deformation and stress distributing nonuniformly in rock mass, and failure localization is inevitable. Generally, a localized failure originates from location of larger creep deformation. Thus to monitor the creep deformation difference of each region interior rock is a valid approach for forecasting rock creep failure.

Bearing this in mind, we firstly used author-developed RLJW-2000 servo compression test machine synchronizing with Digital Speckle Correlation Method (DSCM) [15-17], to learn the difference of creep deformation and failure zone in rock under the uniaxial compressive load, pushing load to steel-plate anchored in rock. We then analysed the relations between the failure pattern and the difference of creep deformation, so as to make better understanding of heterogeneous rock rheologic failure mechanism with different load conditions.

\section{Methodology}

2.1. Digital Speckle Correlation Method. Digital Speckle Correlation Method (DSCM) is employed in this research for 


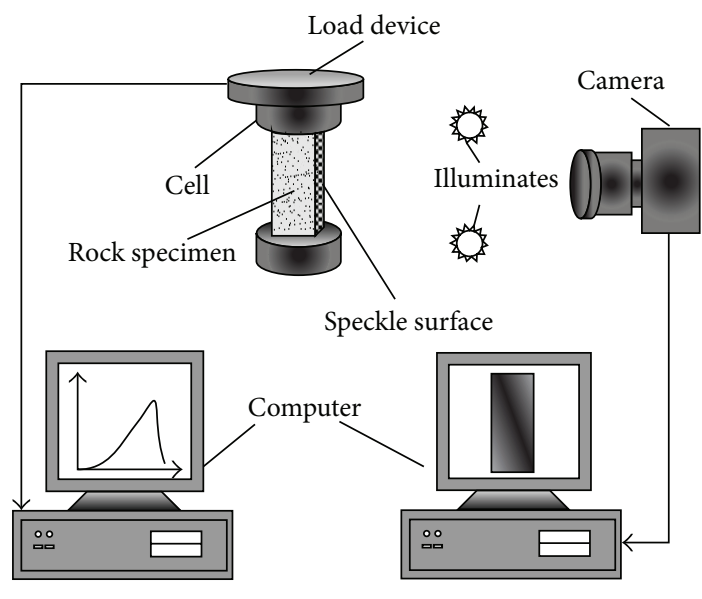

FIGURE 1: DSCM used in rock compression test.

real-time capturing and accurate processing of the speckle images on the specimen surface. It is a noncontact and full-field detection. The basis of DSCM is the matching of points (pixels in an image) between two digital images [18]. In DSCM, the digital speckle images (images with random speckle grains on them) are firstly captured from specimen surface on two deformation states during loading. Then one reference image (before deformation) and one deformed image (after deformation) are processed to obtain the displacement field between these two states. The matching is quantitatively accomplished by correlating the pixel gray level values (intensity) that compose the digital images. The DSCM used for rock mechanics experiments is composed of a CCD Camera, white illuminates, and computers (Figure 1).

Before the test a target zone, rock specimen surface must be sprayed using white paint to a thickness of $1 \mathrm{~mm}$ and then sprayed evenly with black paint to prepare the speckles. The speckles are stable and unchanged in colour during the whole experimental process. The maximum diameter of a black speckle is less than $1 \mathrm{~mm}$. The white and black paints must be dried before being illuminated by one optic illuminator. A digital camera connected to a computer is used to record speckle images in the target zone. Furthermore, in order to control the speckle quality, a speckle image is captured and its grey level is evaluated. As the quality of these speckles is critical for the final accuracy of the DSCM results, the statistical distribution of gray level was employed to evaluate it. Generally, DSCM is accomplished by matching square subsets of pixels, rather than individual pixel, because subsets comprise a wide variation in gray level. The full field displacements are obtained by overlapping the matching subsets.

For the original state (before deformation), the grayscale function is expressed as

$$
\left\{F_{b}\right\}=\left\{F_{b}(x, y), x=1, \ldots, M ; y=1, \ldots, N\right\} ;
$$

the grayscale function of deformed state (after deformation) or shift copy of $\left\{F_{b}\right\}$ is expressed as

$$
\left\{F_{a}\right\}=\left\{F_{a}(x, y), x=1, \ldots, M ; y=1, \ldots, N\right\},
$$

where $M \times N$ is the intensity with pixel.
Assume that $F_{a}(x, y)$ is the shift copy of the original subset $F_{b}(x, y)$ after a deformation, $u_{x}$ and $u_{y}$, which can be considered as constant locally in mesoscale. The relationship between the original and deformed subset is as follow:

$$
F_{a}\left(x+u_{x}, y+u_{y}\right)=F_{b}(x, y)+\xi(x, y),
$$

where $\xi(x, y)$ is random noise which induced by camera, illuminates, and so forth.

To evaluate displacement $u_{x}$ and $u_{y}$, we may minimize the difference between $F_{a}(x, y)$ and $F_{b}(x, y)$ with respect to a trial displacement $u_{x}^{*}$ and $u_{y}^{*}$, this problem is equivalent to evaluate the similarity of two pixel subsets $[15,18-20]$, which can be expressed by correlation coefficient as

$$
\begin{aligned}
& C\left(u_{x}^{*}, u_{y}^{*}\right) \\
& =\frac{\sum_{i=1}^{m} \sum_{j=1}^{m}\left[F_{b}\left(x_{i}, y_{j}\right)-\bar{F}_{b}\right] \times\left[F_{a}\left(x_{i}^{\prime}, y_{j}^{\prime}\right)-\bar{F}_{a}\right]}{\sqrt{\sum_{i=1}^{m} \sum_{j=1}^{m}\left[F_{b}\left(x_{i}, y_{j}\right)-\bar{F}_{b}\right]^{2}} \times \sqrt{\sum_{i=1}^{m} \sum_{j=1}^{m}\left[F_{a}\left(x_{i}, y_{j}\right)-\bar{F}_{a}\right]^{2}}}
\end{aligned}
$$

where $x_{i}^{\prime}=x_{i}+u_{i x}, y_{j}^{\prime}=y_{j}+u_{j y}$,

$$
\begin{aligned}
& \bar{F}_{b}=\frac{1}{m^{2}} \sum_{i=1}^{m} \sum_{j=1}^{m} F_{b}\left(x_{i}, y_{j}\right), \\
& \bar{F}_{a}=\frac{1}{m^{2}} \sum_{i=1}^{m} \sum_{j=1}^{m} F_{a}\left(x_{i}^{\prime}, y_{j}^{\prime}\right)
\end{aligned}
$$

is the average of intensity of $m \times m$ pixel subset.

If the grey level of black speckles in the target zone is not a normal distribution, the specimen should be abandoned. Note that the speed of image collection depends on the moving conditions of a specimen and the expected computing precision. It must be pointed out that a subpixel level search must be completed to obtain a 0.01 pixel displacement measurement precision. Displacement of the object can be measured through comparing all the point pairs in these two speckle images. The full-field displacements are obtained by overlapping the matching subsets finally.

\subsection{Creep Experimental Test}

2.2.1. Uniaxial Compressive Creep Test. Uniaxial compressive test is a conventional approach for observing rock failure pattern. Gathering uniaxial creep compressive test and DSCM is a valid approach to observe rock failure evolution in creep. This kind of test should be strict in accordance with the procedures. Primarily, the conventionally uniaxial compressive test was carried out to obtain the rock basic mechanical parameters: uniaxial compressive strength, $\sigma_{c}(\mathrm{Mpa})$; Young's modulus, $E$ (Mpa); Poisson's ratio, $\mu$. Extensometers with $50 \mathrm{~mm}$ in diameter were adopted to measure the longitudinal displacement. Then the specimens of rock were cut into cuboids with $40 \mathrm{~mm}$ long, $40 \mathrm{~mm}$ wide, and $80 \mathrm{~mm}$ high, so as to be convenient for DSCM test. After that, on one surface of specimen, speckle paint with $1 \mathrm{~mm}$ thick was 


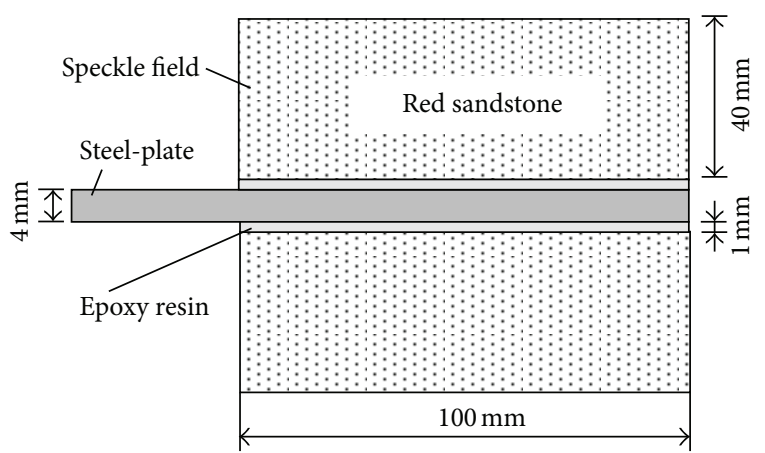

FIGURE 2: Section of steel-plate anchored rock specimen.

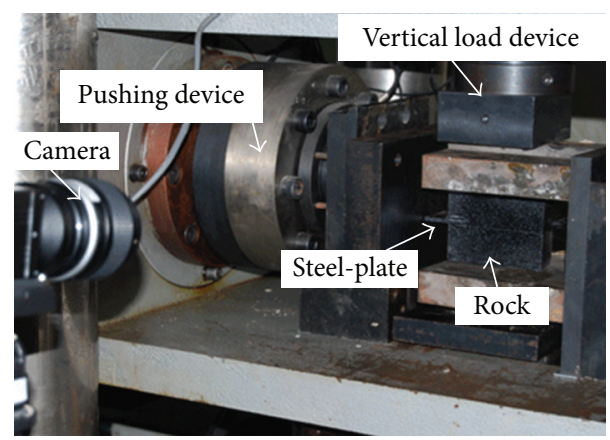

FIGURE 3: Creep pushing test of steel-plate anchored in rock.

sprayed. At last, the uniaxial creep compressive test was carried out by RLJW-2000 servo compression test machine (developed by authors) synchronizing with DSCM. In order to responsibly determine the creep loading stage, the average uniaxial compressive strength of three specimens was needed to obtain firstly.

The creep test loading was in the manner of stage by stage. At first, the displacement control mode was kept unchanged till the load is stable. Then the pressure load mode with $50 \mathrm{~N} / \mathrm{S}$ in loading rate was adopted. The first stage load is about 20 percent of $\sigma_{c}$. After that, 10 percent of $\sigma_{c}$ was enhanced for each stage, until the ultimate strength, $\sigma_{c}$, reached. In each loading stage, the constant time was kept for 8 hours long. The time interval for load and displacement data collection was 1 minute. At the same time, digital speckle correlation method was adopted to obtain the displacement field during the rock rheologic process (Figure 1). Before photographing, the load-host computer and image collection-host computer were accurately kept in the same pace. In the period of load increasing, the speckle image was collected at the rate of 5 frame/s. During the constant load stage, the speckle image was collected at the rate of $5 \mathrm{~min} /$ frame.

\subsubsection{Creep Test on Pushing Steel-Plate Anchored in Rock.} In deep underground engineering, anchored rock failure in creep often occurs accompanying anchors being pushed out. This kind failure pattern should be learned by special creep test on pushing steel anchored in rock. It is some different from the uniaxial compressive creep test mentioned

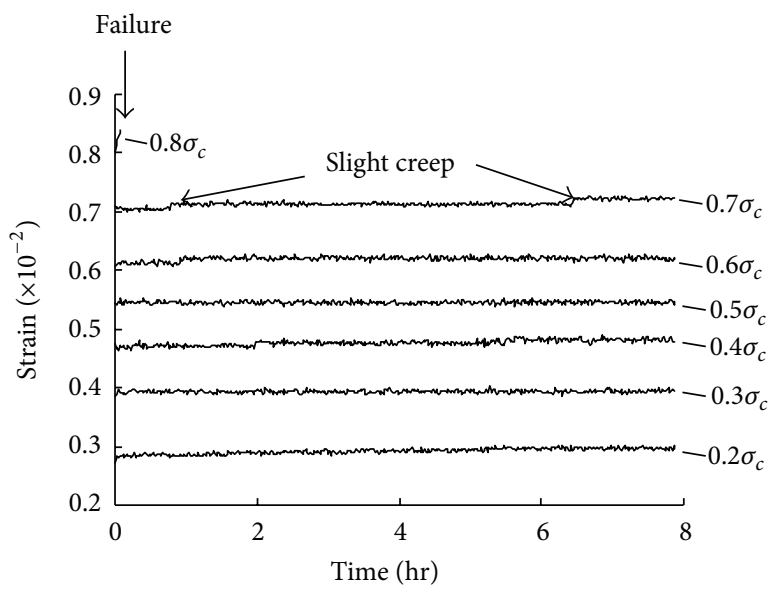

FIGURE 4: Creep strain-time curve of uniaxial compressive test.

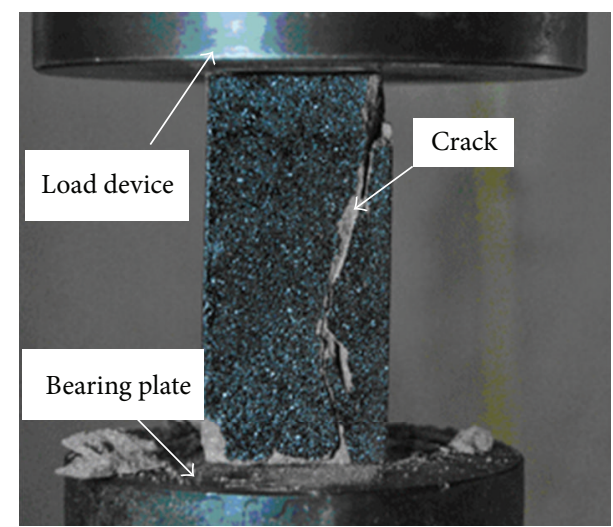

FIGURE 5: Breaking state of uniaxial compressive rock specimen.

earlier. At first, steel-plate anchored rock specimens were manufactured. In a specimen, a steel-plate with $4 \mathrm{~mm}$ thick, $25 \mathrm{~mm}$ wide, and $150 \mathrm{~mm}$ long was anchored in the centre. The upper layer and lower layer were sandstones which were cut into cuboids with $40 \mathrm{~mm}$ thick, $25 \mathrm{~mm}$ wide, and $100 \mathrm{~mm}$ long. The interface between rock and steel-plate was adhered by epoxy resin. Then on the specimen surface, speckle paint with $1 \mathrm{~mm}$ thick was sprayed (Figure 2). After then, pushing test synchronizing with DSCM was carried out. The detail procedures were as follows. Firstly, a specimen was placed on the bearing platform of RLJW-2000 servo compression test machine, and steel-plate was ordered in the horizontal direction. Secondly, a vertical pressure with $5 \mathrm{Mpa}$ was applied and was kept constantly. Thirdly, a pushing load device was applied to the out end of steel-plate horizontally (Figure 3). The creep pushing load was in the manner stage by stage. The pushing load first of stage was applied to $10 \mathrm{kN}$ at a rate $20 \mathrm{~N} / \mathrm{s}$ gradually and then was kept constantly within 6 hours. From the second stage, the load increment was always kept on $5 \mathrm{kN}$, until the steel-plate was pushed out. During the load increasing period, the load and displacement sampling interval was 1 minute, and the speckle image was collected at the rate of 5 frame/s correspondingly. During the period of load kept constantly, the speckle image was collected at 


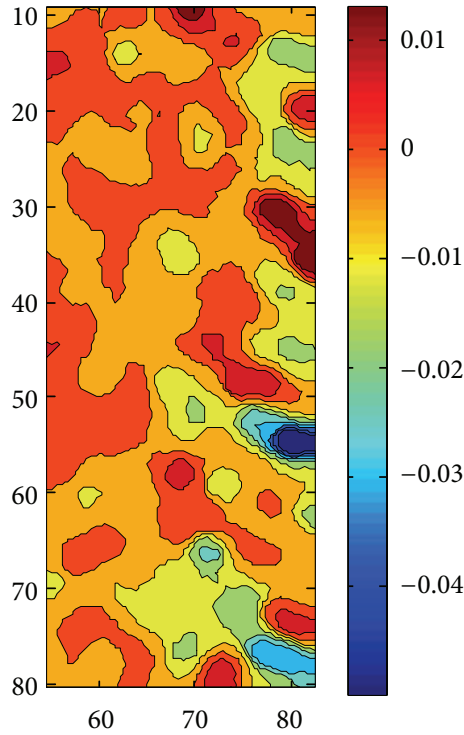

(a) Horizontal displacement ( $\mathrm{mm}$ )

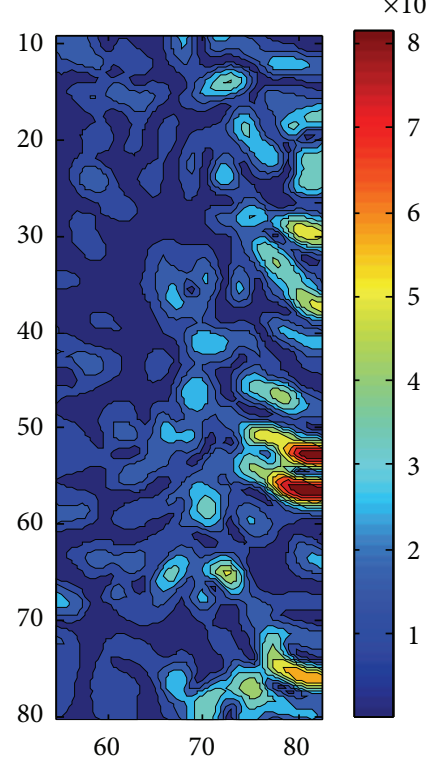

(b) Vertical displacement (mm)

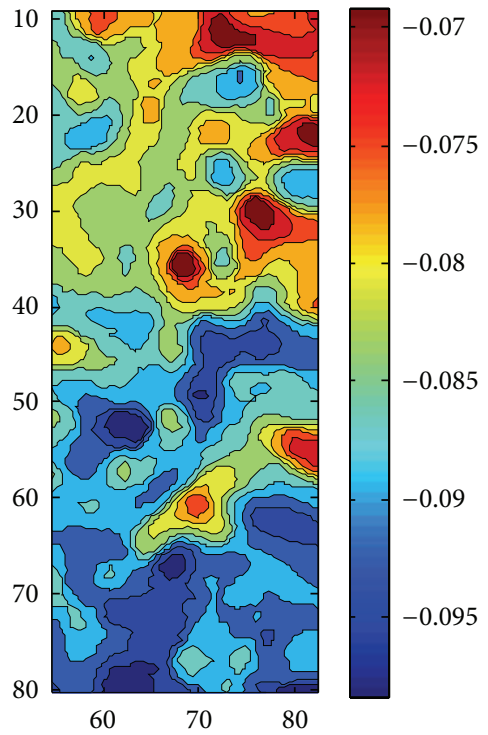

(c) Shear strain

FIgURE 6: Deformation field under the load level of $12.65 \mathrm{Mpa}, 0.2 \sigma_{c}$.

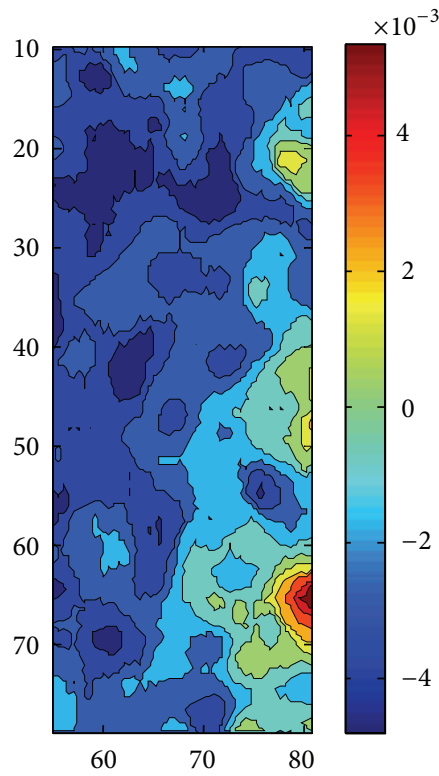

(a) Horizontal displacement $(\mathrm{mm})$

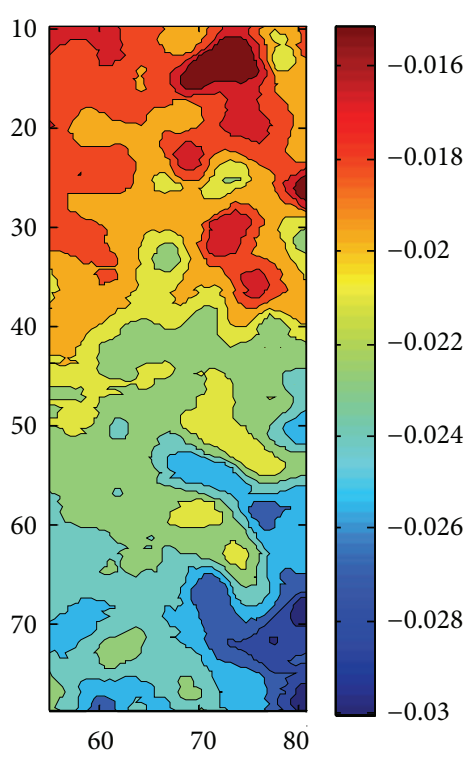

(b) Vertical displacement (mm)

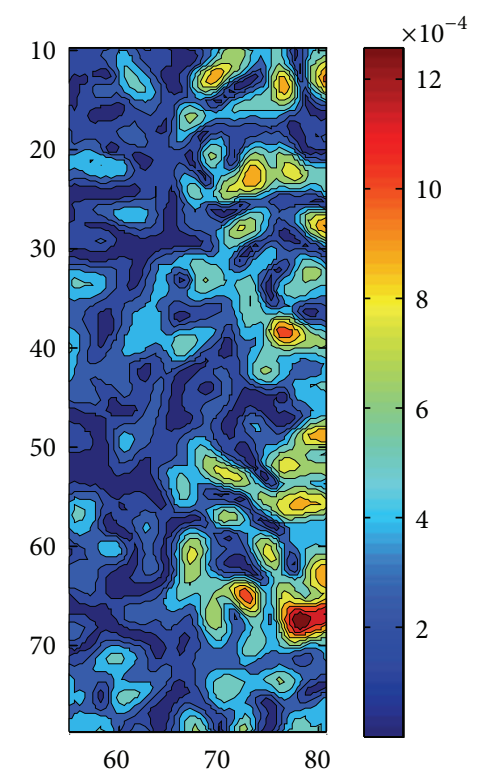

(c) Shear strain

Figure 7: Deformation field under the load level of $37.965 \mathrm{Mpa}, 0.5 \sigma_{c}$.

the rate of $5 \mathrm{~min} /$ frame. At last, the failure pattern as well as displacement field evolution of a steel-plate anchored rock specimen was obtained.

\section{Results and Discussion}

3.1. Uniaxial Creep Compressive Test Results. Three mudstone rock specimens were sampled from the Kouzidong Mine situated at Huainan city, Anhui province, China. By conventional uniaxial compressive test, we obtained their average uniaxial compressive strength, $\sigma_{c}$, being 63.26 Mpa. Other new three specimens were used to do the uniaxial creep compressive test. The loading stages were $0.2 \sigma_{c}, 0.3 \sigma_{c}, 0.4 \sigma_{c}, 0.6 \sigma_{c}, 0.7 \sigma_{c}$, and $0.8 \sigma_{c}$, correspondingly. The total creep test time went through 48.1 hours. The typical curve of axial strain-time was shown in Figure 4. It was found that when the compressive load was lower than $0.6 \sigma_{c}$, the creep strain was less; when the load level arrived at $0.7 \sigma_{c}$, the creep strain began to 


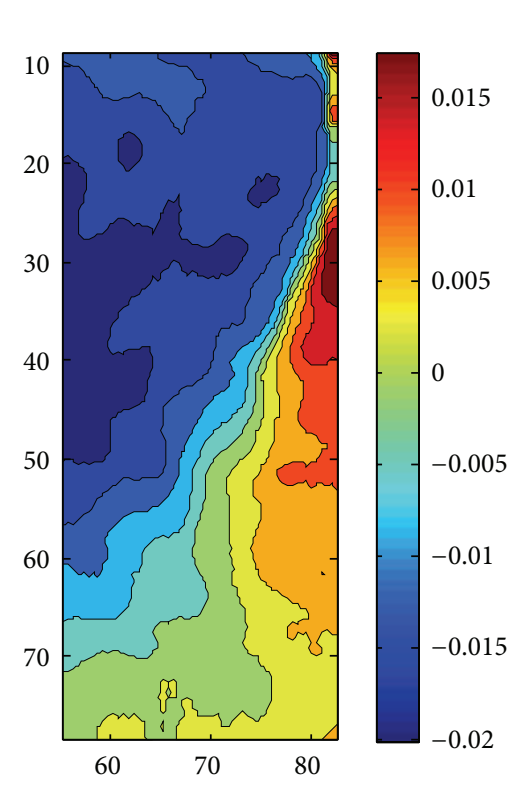

(a) Horizontal displacement ( $\mathrm{mm})$

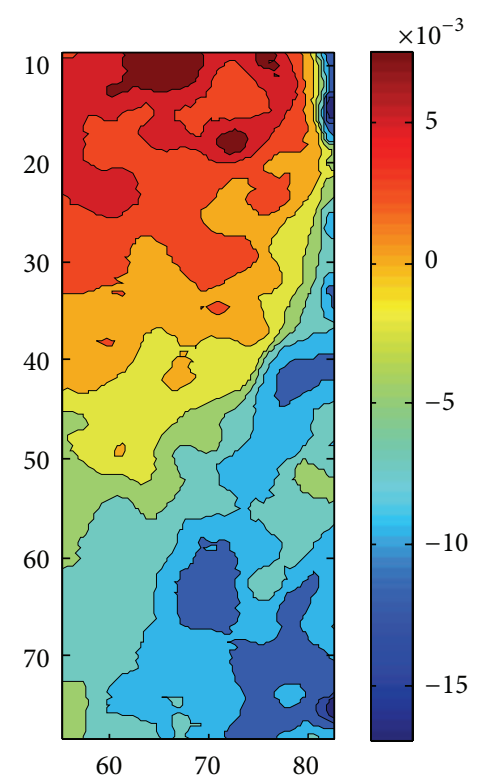

(b) Vertical displacement $(\mathrm{mm})$

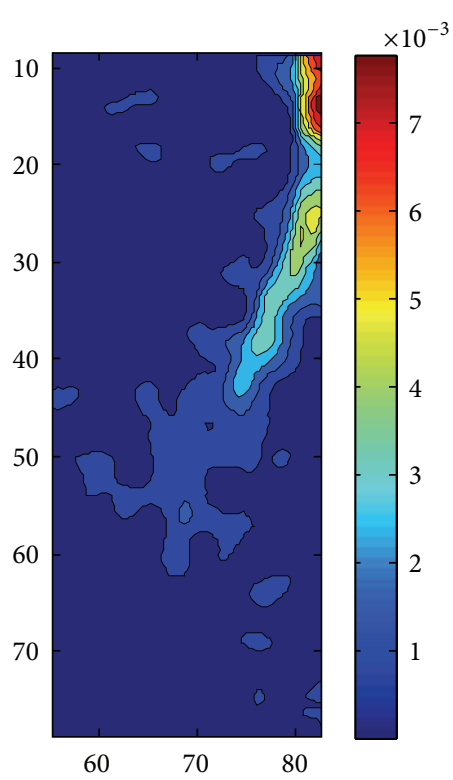

(c) Shear strain

Figure 8: Deformation field under the load level of $56.94 \mathrm{Mpa}, 0.8 \sigma_{c}$.

increase slightly in a jump mode; when the load level arrived at $0.8 \sigma_{c}$, the creep strain increased rapidly. After 0.1 hour, the specimen abruptly fractured in a shear mode (Figure 5). Thus, mudstone rock was in the elastic deformation at the low loading level. When the load reached its limit value, strong creep deformation happened and leaded to the rock fracturing rapidly. The creep deformation duration was short.

At the same time, we obtained the horizontal and vertical displacement fields, and shear strain field. We selected the three states while load arriving at $0.2 \sigma_{c}, 0.5 \sigma_{c}$ and $0.8 \sigma_{c}$ to analyse the creep deformation distribution. When load was at the lower level, $0.2 \sigma_{c}$, the deformation in the specimen was less in magnitude and distributed inhomogeneously and randomly, and deformation concentrated locally due to the heterogeneity of rock in mesoscale (Figure 6). When load level arrived at $0.5 \sigma_{c}$, the deformation field became ordering (Figure 7) compared with the lower load level, $0.2 \sigma_{c}$. At this load level, two horizontal displacement clusters formed in the left-up and right-down regions separately. The shear strain cluster gathered more and more prominently. This phenomenon can not be indicated by creep strain-time curve. When load level arrived at $0.8 \sigma_{c}$, as the displacement clusters became more ordering, a narrow deformation concentrating band formed (Figure 8), which led to the specimen fractured after 0.1 hour. Both displacement field and shear strain field were in keeping with the creep strain-time curve (Figure 4).

Just as mentioned earlier, rock is a kind of natural heterogeneous material in mesoscale. A lot of detects or disordered mini-fissures existed in it due to the long time geological movement. For a rock sample, when compressive load is in a low level, the fissures are easy to close, and the displacement field within rock is disordered; so rock is dominated by elastic deformation in macro-scale at this stage. As the load level increases gradually, some damages originating from defects or fissures occur, which cause the displacement or strain field concentrating locally, several deformation clusters gather. But the macrocreep deformation is still not distinct in displacement-time curve. This is the period of creep damage accumulation before rock begins macrofailure. In this period the creep deformation field evolves to gather some ordered clusters. This behaviour may be considered as a useful indication for forecasting the rock failure in a long term. Thus, DSCM is valid to remedy the imperfection that conventional creep test cannot reflect the deformation field within rock in laboratory, which extends the function of conventional rock creep test indeed. However, in macrorock engineering, how to adopt such techniques as DSCM to monitor local creep damage evolution within rock is a challenge work. It must be pointed out that such a situation as rock filled with water or rock chemical reaction with other medium was not considered.

As for the rationale of failure bands formation, it can be explained by Mohr-Coulomb criterion [21] as

$$
\tau=\sigma_{n} \tan \varphi+C,
$$

where $\tau$ and $\sigma_{n}$ are the shear stress and normal at failure plane which can be easily obtained under a compressive load condition, $C$ is cohesion, and $\varphi$ is angle of internal friction. The Mohr envelope represents the true shape of the failure curve (Figure 9). Mohr's stress circle can be determined by maximum and minimum principal stresses: $\sigma_{1}$ and $\sigma_{3}$. For the case of uniaxial compressive test, $\sigma_{3}=0$.

One easily finds from this theory that the failure plane forms the angle $\left(45^{\circ}+\varphi / 2\right)$ to the plane against which the major principal stress operates, and this does not agree with the axial splitting. Let us start by examining the simple approach that the strength of rock can be expressed in terms 


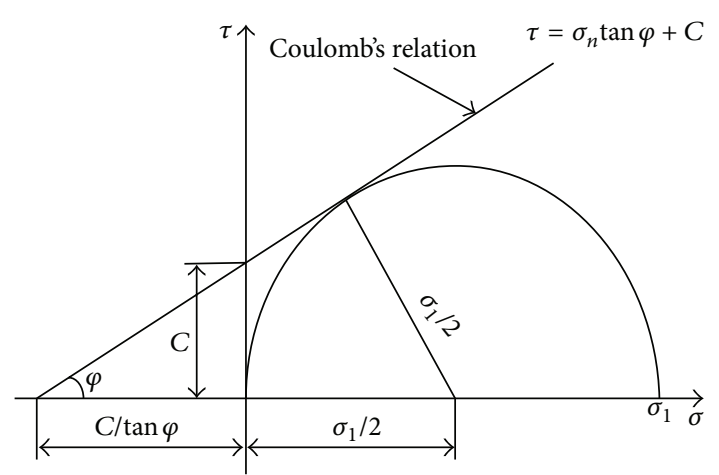

FIGURE 9: Stress failure at Coulomb-Mohr criterion.

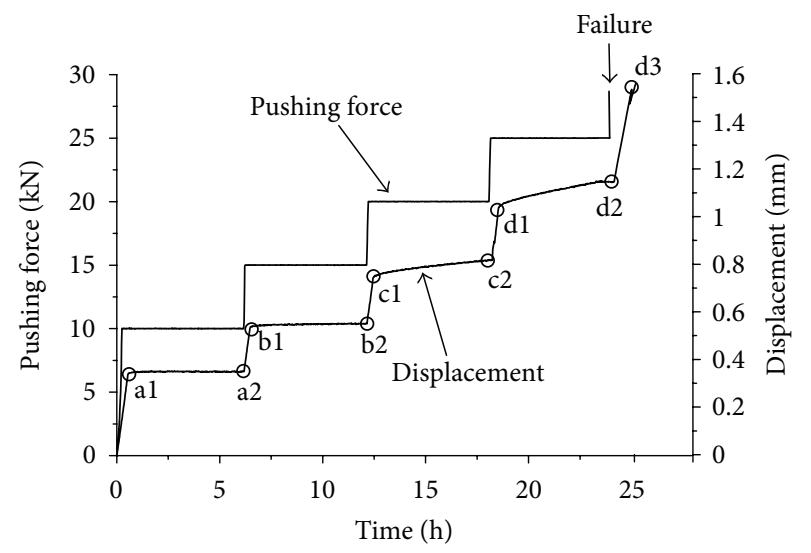

Figure 10: Pushing force-displacement-time curve.

of a cohesion term and a friction term, from a mesomechanical point of view. Assume that the former represents the crystal matrix of the smallest rock units and the latter to mirror the influence of discrete discontinuities of different extension. Mobilization of the two strength components requires very different amounts of strain. Naturally, if continuous plane weaknesses extend across a rock volume, separating blocks, shearing by relative movement of the blocks may take place without bringing the rock material in the blocks into a critical state. This case leads to shear failure. Not surprisingly, rock is a kind of inhomogeneous material, and many fissures are contained in it randomly. This causes cohesion decreasing and shear failure happening easily at last, Coulomb-Mohr criterion is satisfied.

3.2. Creep Test on Pushing Steel-Plate Anchored in Rock. In the creep pushing test, five stages of pushing load 10, 15, 20, 25, and $30 \mathrm{kN}$ were applied, and the corresponding displacement during each stage was named after al-a2, b1-b2, c1-c2, and d1d2-d3 (Figure 10). Before pushing force was less than $20 \mathrm{kN}$, creep deformation was little, and the composite specimen was in an elastic deformation state. When pushing force arrived at $20 \mathrm{kN}$, creep displacement occurred and increased as the pushing force level was enhanced. When pushing force arrived at $25 \mathrm{kN}$, crack began to occur, and creep displacement increased rapidly. After pushing force arrived at

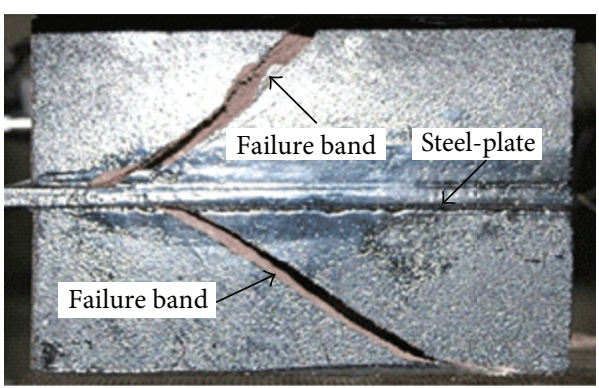

FIGURE 11: Creep failure pattern of pushing steel-plate anchored in rock.

$27.5 \mathrm{kN}$, the steel-plate was pushed out quickly accompanying strong creep deformation, and two win-shape macrocracks formed (Figure 11) at last.

At the same time, we obtained the horizontal displacement field and shear strain field by DSCM. Five stages of pushing force $10,15,20,25$, and $27.5 \mathrm{kN}$ were adopted to analyse the evolution of creep deformation field. Before pushing force arrived at $15 \mathrm{KN}$, the creep deformation was less in magnitude and distributed inhomogenously and randomly and concentrated locally because of the heterogeneity of rock in mesoscale (Figures 12-13). When pushing force arrived at $20 \mathrm{kN}$, the displacement field tended to be ordering, and shear strain concentrated discontinuously along the interface between steel-plate and rock (Figure 14). While pushing force arrived at $25 \mathrm{kN}$, the horizontal displacement and shear strain concentrated continuously along the interface between steelplate and rock, and a new narrow shear strain band formed in the upper layer (Figure 15), which indicated the first narrow shear band occurred. Unfortunately, when pushing force arrived at $27.5 \mathrm{kN}$, the another new narrow shear strain band formed in the lower layer was not recorded because of the sudden failure of switch to illuminators. The duration from strong creep deformation to shear band formed, till to steelplated was pushed out is short, which is consistent with that obtained by conventional creep test.

In order to verify the correctness of two win-shape failure bands formed (Figure 11), numerical simulations were performed by using Particle Flow Code $\left(\mathrm{PFC}^{2 \mathrm{~d}}\right)$ [22]. The results showed that the formation of shear band went through the process: crack initiation from original defect $\rightarrow$ cluster generation $\rightarrow$ cluster increasing $\rightarrow$ cluster interfusion $\rightarrow$ core or continuous zone. At last, the two win-shape failure bands formed (Figure 16), which is similar with laboratory test result.

The test process of pushing steel-plate anchored in rock showed that when pushing force was at a low level, the displacement field was disordered, and rock was in elastic deformation. As pushing force increased, some damages originated from some defects, which caused the displacement or strain concentrating locally, and several deformation clusters gathered, although macrocreep deformation was not distinct. Similarly, because the duration from strong creep deformation to failure zone formed is short, only through 


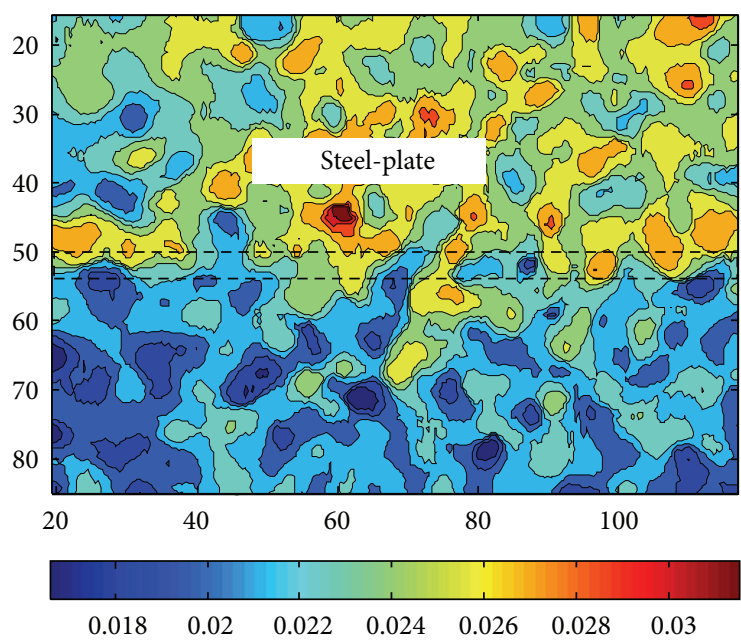

(a) Horizontal displacement (mm)

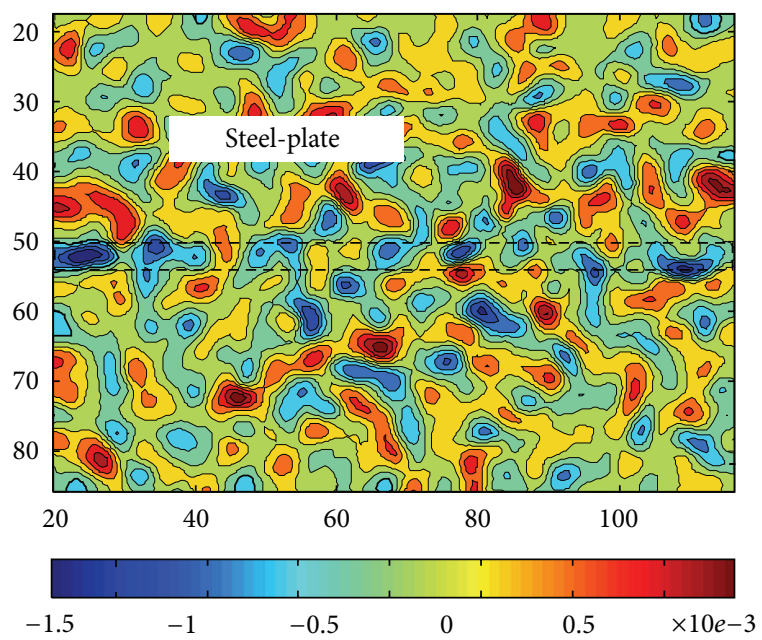

(b) Shear strain

FIGURE 12: DSCM results at pushing force $10 \mathrm{kN}$.

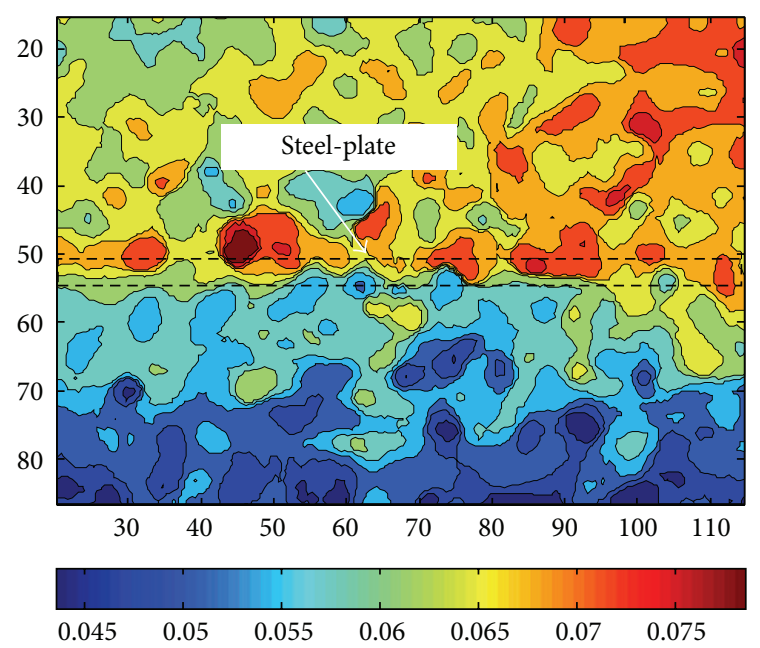

(a) Horizontal displacement (mm)

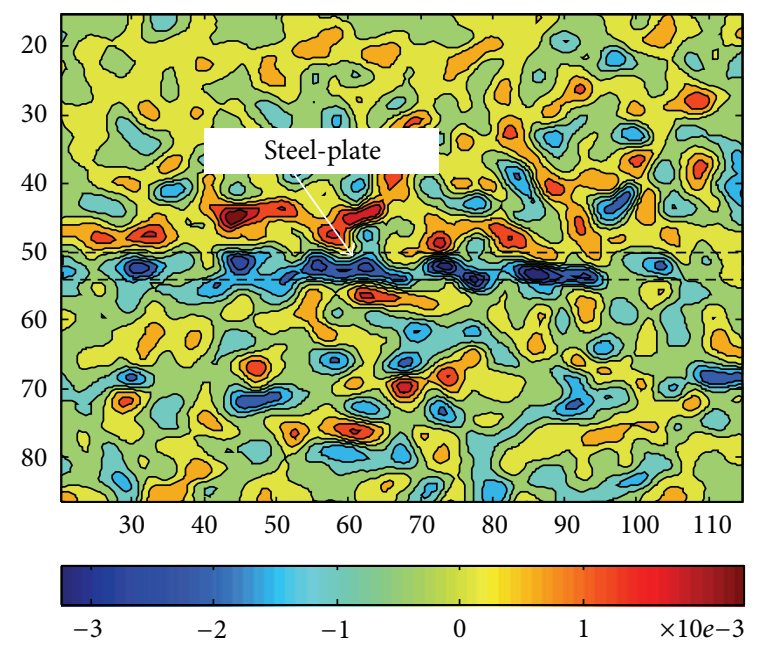

(b) Shear strain

FIGURE 13: DSCM results at pushing force $15 \mathrm{kN}$.

observing the shortly strong creep deformation to forecast the rock failure is too hasty.

Fortunately, DSCM can be easily used to monitor all the evolution progress of creep deformation field, which provides a wealth of information for forecasting rock failure indeed. Thus, such techniques as DSCM may bring about some new monitoring approaches in anchored rock engineering.

\section{Conclusions}

The aim of the approach of RLJW-2000 servo test synchronizing with DSCM was adopted to investigate the rock failure pattern and creep deformation. By comparing with the past investigation, this research contains at least three original aspects.
(1) The RLJW-2000 servo test synchronizing with DSCM on creep failure of uniaxial compression and of pushing steel-plate contained in rock was performed firstly.

(2) The deformation field evolution from creep damage accumulation to macrofailure under the uniaxial creep compression load condition was obtained.

(3) The displacement field evolution in rock and rock failure pattern during creep pushing steel-plate anchored in rock were obtained.

The investigations showed the following.

(1) For a uniaxial compressive specimen, when load arrives at $0.5 \sigma_{c}$, ordered displacement clusters form, which is ahead of the macrocreep strain occurring in a slight jump mode when load arrives at $0.7 \sigma_{c}$. 


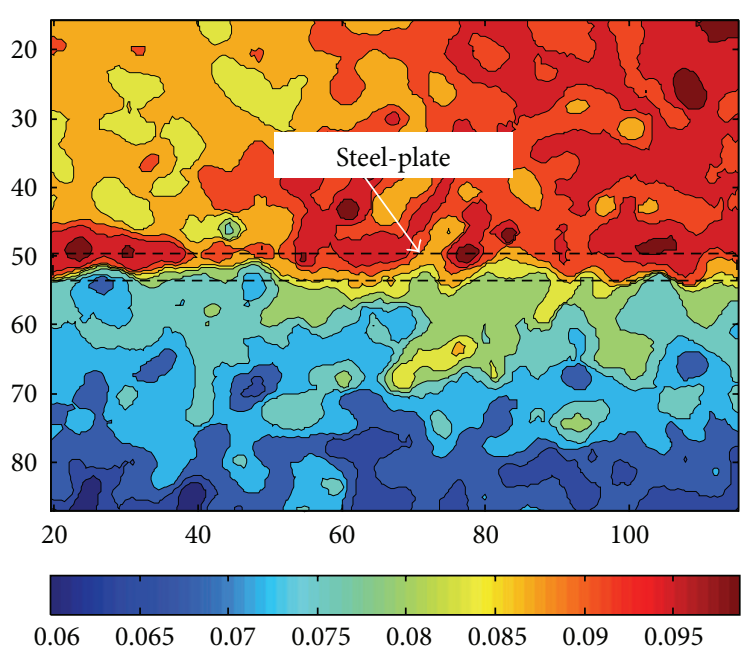

(a) Horizontal displacement $(\mathrm{mm})$

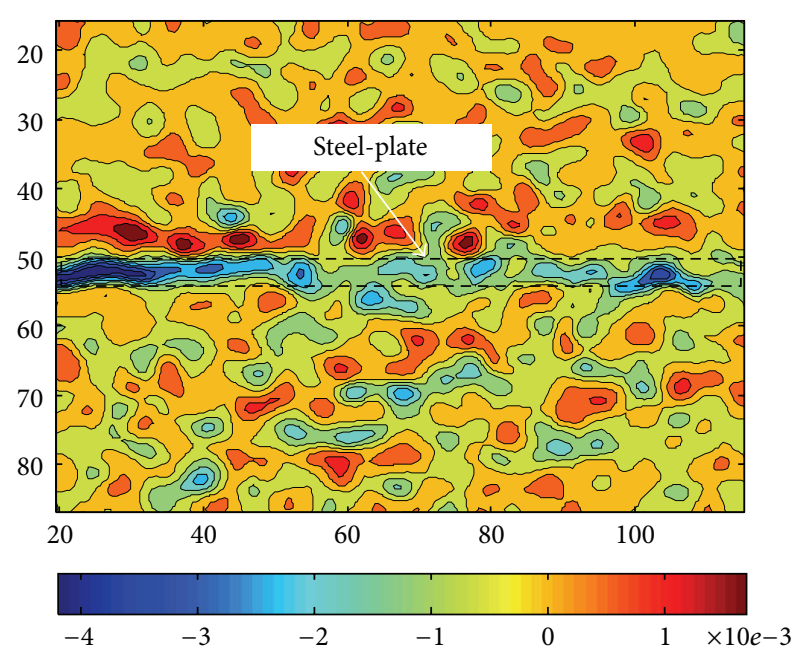

(b) Shear strain

FIGURE 14: DSCM results at pushing force $20 \mathrm{kN}$.

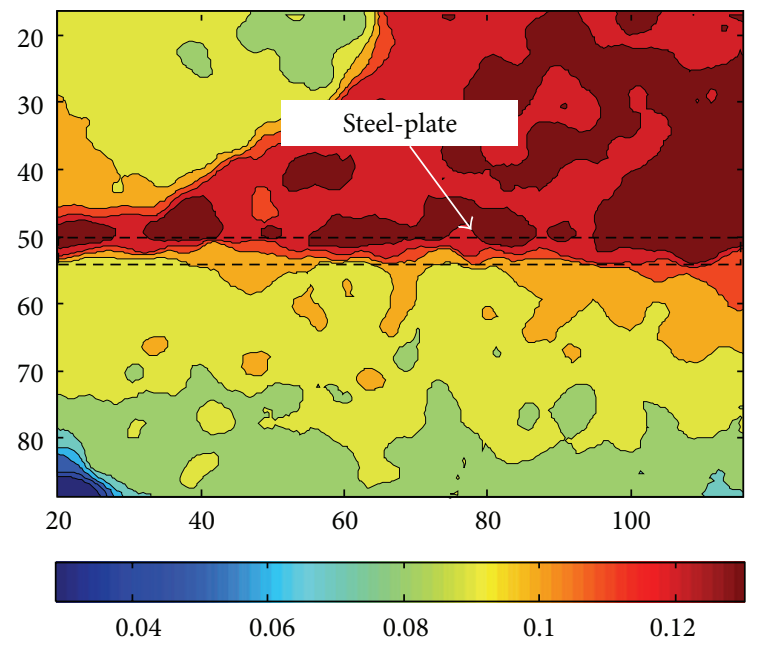

(a) Horizontal displacement $(\mathrm{mm})$

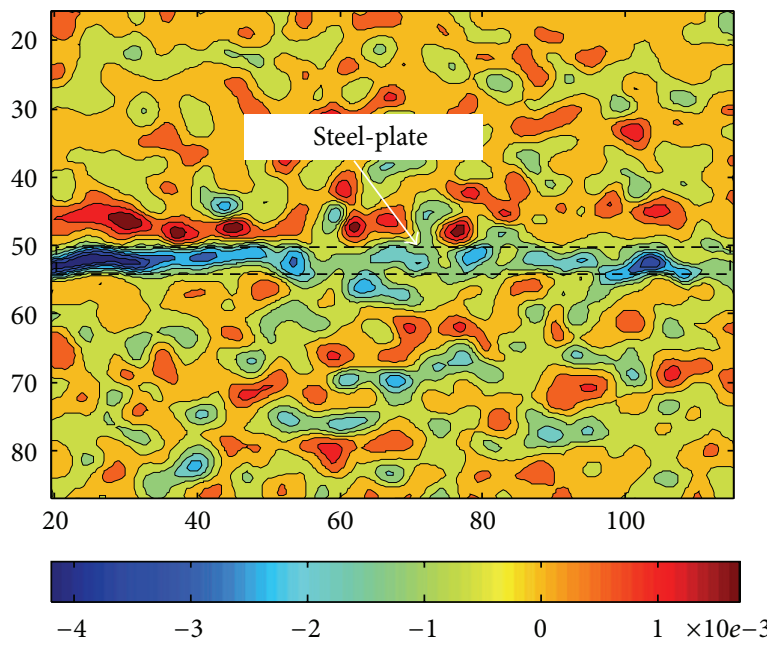

(b) Shear strain

FIGURE 15: DSCM results at pushing force $25 \mathrm{kN}$.

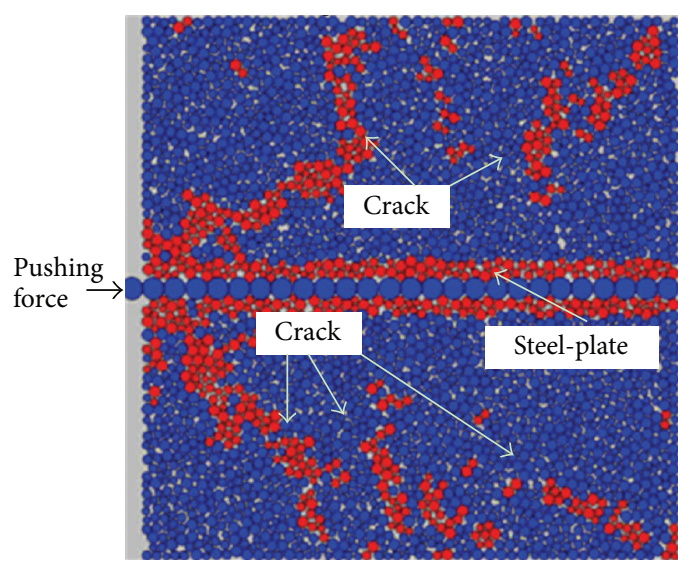

(a) Before being pushed out

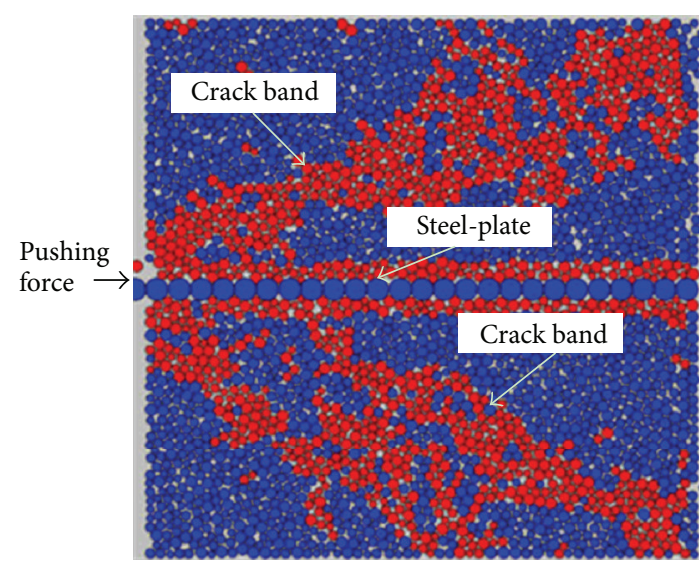

(b) After being pushed out

FIGURE 16: Simulations on failure pattern of steel-plate being pushed out. 
When the load level arrives at its threshold, $0.8 \sigma_{c}$, the creep strain increased rapidly, and the displacement clusters shape a narrow band. After that, the specimen abruptly fractures in a shear mode.

(2) In the creep pushing steel-plate test, before pushing force arrives at $20 \mathrm{kN}$, the creep deformation is little, and the composite specimen is in an elastic deformation state. When pushing force arrives at $25 \mathrm{kN}$, crack begins to occur, creep displacement increases rapidly, the horizontal displacement field as well as shear strain field not only concentrates continuously along the interface between steel-plate and rock, but also a new narrow band concentrates in the upper layer. When pushing force arrives at $27.5 \mathrm{kN}$, another new narrow shear deformation band forms in the lower layer. After that, the steel-plate is pushed out quickly accompanying strong creep deformation.

(3) The deformation field cluster is ahead of the macrocreep deformation, and so the variation of deformation field can be used to predicate the macrocreep deformation occurring of rock.

(4) The duration from strong creep deformation to failure of rock is short. Such a technique as DSCM may make some new contributions on how to monitor and forecast rock failure in engineering.

\section{Acknowledgments}

This work was supported in part the National Basic Research Program of China (973 Program) Grant no. 2010CB226805, China Natural Science Fund (nos. 51074099, 51274133, and 51174129), Doctoral Scientific Fund Project of the Ministry of Education of China (no. 20123718110013), Shandong Province Natural Science Fund (no. ZR2012EEZ002), and SDUST Research Fund (no. 2010KYTD105).

\section{References}

[1] M. S. Paterson, "Experimental deformation and faulting in Wombeyan marble," Geological Society of America Bulletin, vol. 69, pp. 465-467, 1958.

[2] K. Mogi, "Deformation and fracture of rocks under confining pressure: elasticity and plasticity of some rocks," Bulletin of the Earthquake Research Institute, vol. 43, pp. 349-379, 1965.

[3] K. Mogi, "Pressure dependence of rock strength and transition from brittle fracture to ductile flow," Bulletin of the Earthquake Research Institute, vol. 44, pp. 215-232, 1966.

[4] H. C. Heard, "Transition from brittle fracture to ductile flow in Solenhofen limestone as a function of temperature, confining pressure, and interstitial fluid pressure," Geological Society of America Bulletin, vol. 79, pp. 193-226, 1960.

[5] J. A. Hudson, Comprehensive Rock Engineering, Pergamon Press, Oxford, UK, 1993.

[6] D. F. Malan, "Manuel Rocha medal recipient simulating the time-dependent behaviour of excavations in hard rock," Rock Mechanics and Rock Engineering, vol. 35, no. 4, pp. 225-254, 2002.

[7] D. T. Griggs, "Creep of rocks," Journal of Geology, vol. 37, pp. 225-251, 1939.
[8] Y. Li and C. Xia, "Time-dependent tests on intact rocks in uniaxial compression," International Journal of Rock Mechanics and Mining Sciences, vol. 37, no. 3, pp. 467-475, 2000.

[9] P. Xu and X. L. Xia, "Experimental test on granite in Three George Project," Chinese Journal of Geotechnical Engineering, vol. 18, no. 4, pp. 63-67, 1996.

[10] X. L. Xia, P. Xu, and X. L. Ding, "Rheological characteristics of rock and stability rheological analysis for high slope," Chinese Journal of Rock Mechanics and Engineering, vol. 15, no. 4, pp. 312-322, 1996.

[11] T. B. Zhao, Y. L. Tan, S. S. Liu, and Y. X. Xiao, "Analysis of rheological properties and control mechanism of anchored rock," Rock and Soil Mechanics, vol. 33, no. 6, pp. 1730-1734, 2012.

[12] X. Ge, J. Ren, Y. Pu, W. Ma, and Y. Zhu, "Real-in-time CT triaxial testing study of meso-damage evolution law of coal," Chinese Journal of Rock Mechanics and Engineering, vol. 18, no. 5, pp. 497-502, 1999.

[13] X. R. Ge and J. X. Ren, "Study on the real in time CT test of the rock meso-damage propagation law," Science in China, Series E, vol. 30, no. 2, pp. 104-111, 2000.

[14] J. Ren and X. Ge, "Study of rock meso-damage evolution law and its constitutive model under uniaxial compression loading," Chinese Journal of Rock Mechanics and Engineering, vol. 20, no. 4, pp. 425-431, 2001.

[15] W. H. Peters and W. F. Ranson, "Digital imaging techniques in experimental stress analysis," Optical Engineering, vol. 21, no. 3, pp. 427-431, 1982.

[16] I. Yamaguchi, "A laser-speckle strain gauge," Journal of Physics E, vol. 14, no. 11, article 012, pp. 1270-1273, 1981.

[17] Y. M. Song, S. P. Ma, X. B. Wang, and X. Wang, "Experimental investigation on failure of rock by digital speckle correlation method," Chinese Journal of Rock Mechanics and Engineering, vol. 30, no. 1, pp. 1701-1176, 2011.

[18] Y. H. Zhao and S. P. Ma, "Deformation field around the stress induced crack area in sandstone by the digital speckle correlation method," Acta Geologica Sinica, vol. 83, no. 3, pp. 661-672, 2009.

[19] M. A. Sutton, S. R. Meneill, and J. Jang, "Effects of sub-Pixel images to ration on digital correlation error estimation," Optical Engineering, vol. 27, no. 10, pp. 870-877, 1988.

[20] J. Zhang, G. Jin, S. Ma, and L. Meng, "Application of an improved subpixel registration algorithm on digital speckle correlation measurement," Optics and Laser Technology, vol. 35, no. 7, pp. 533-542, 2003.

[21] J. C. Jaeger, "Shear failure of anisotropic rocks," Geological Magazine, vol. 97, pp. 65-72, 1960.

[22] P. A. Cundall and O. D. L. Strack, "Discrete numerical model for granular assemblies," Geotechnique, vol. 29, no. 1, pp. 47-65, 1979. 

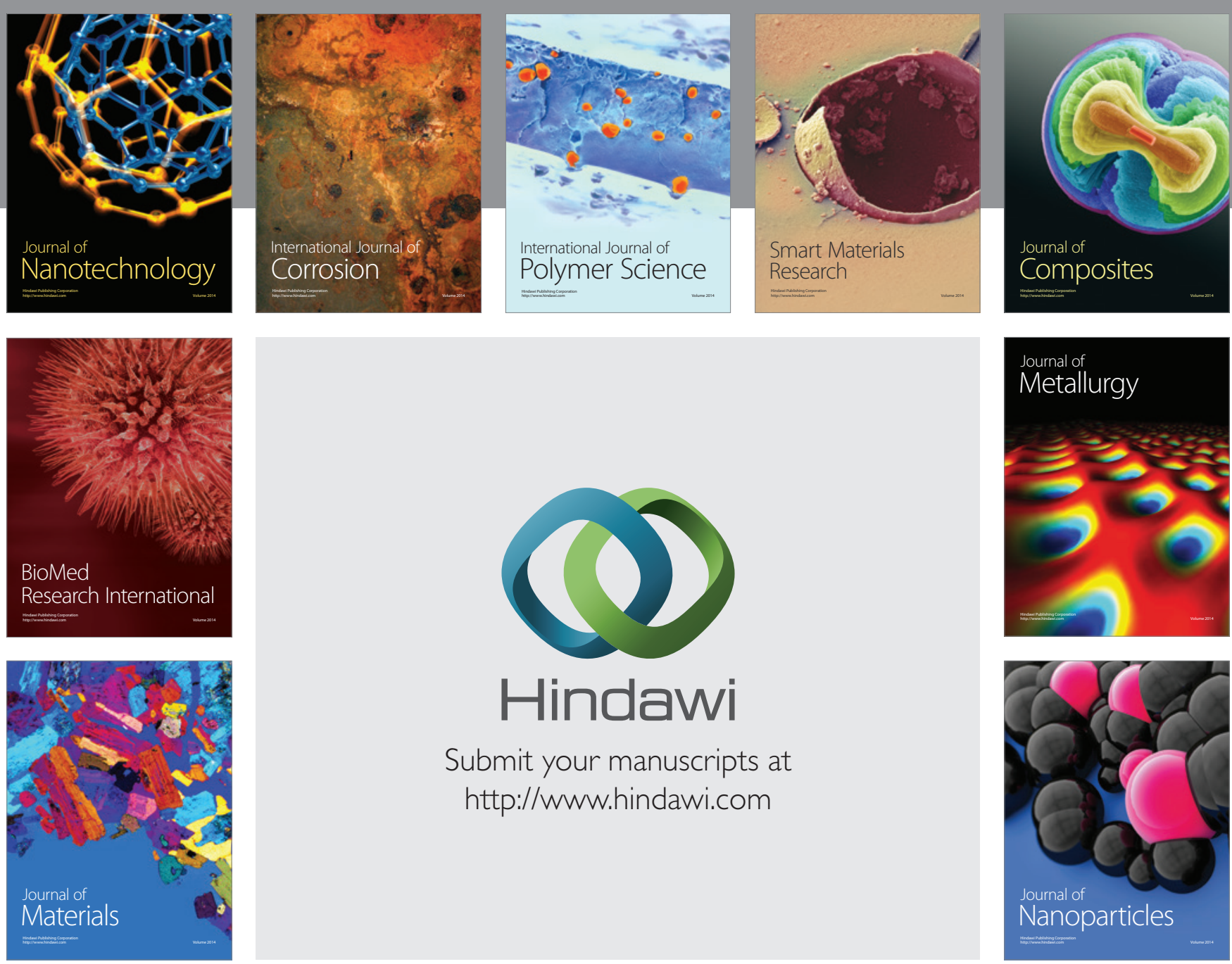

Submit your manuscripts at http://www.hindawi.com
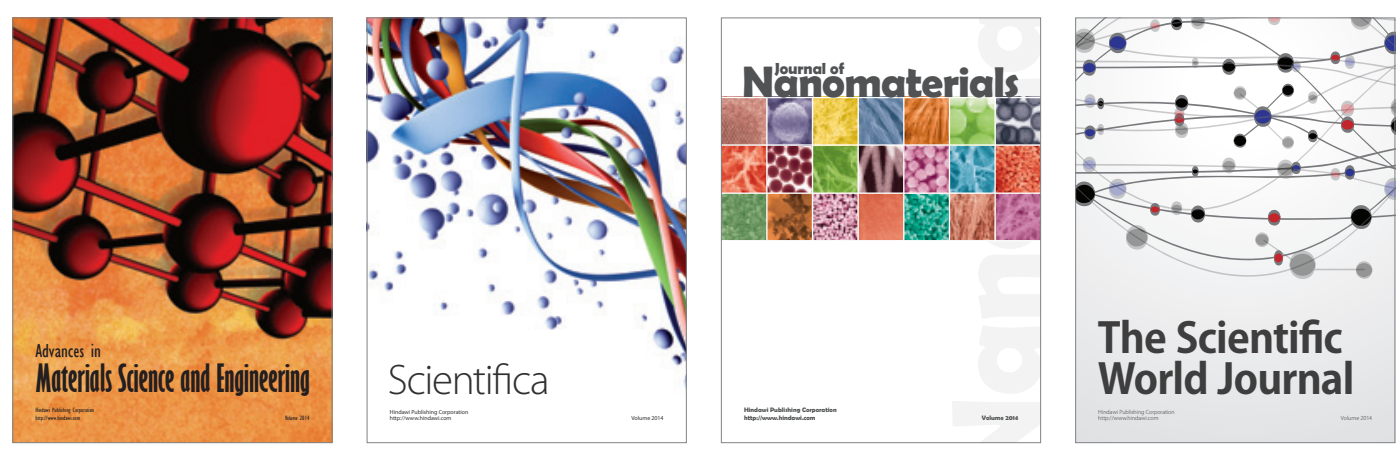

\section{The Scientific World Journal}
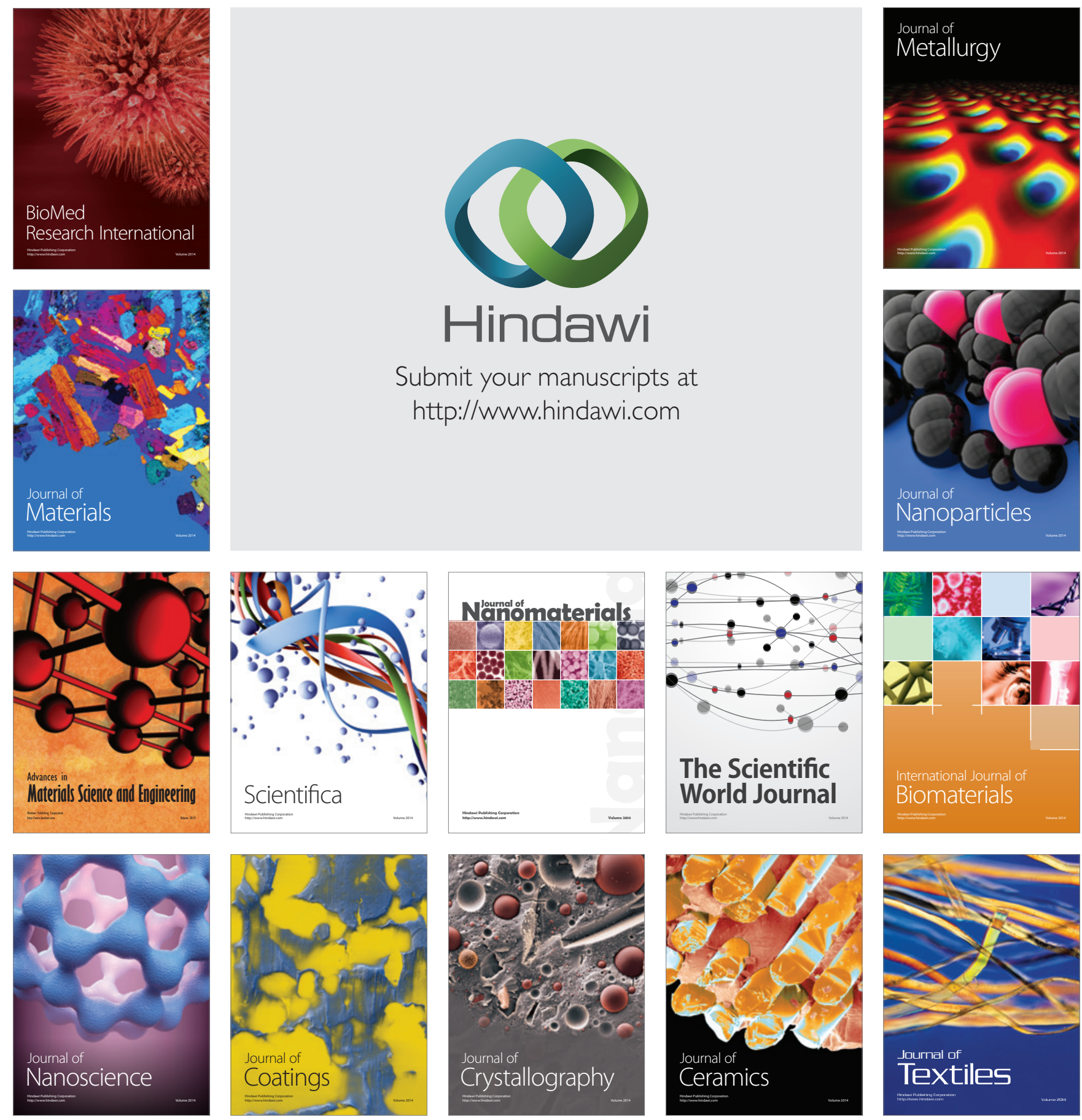